\title{
Exploring the relationship between geriatric patients and their carers through portraiture: giving, receiving, observing \& witnessing care (GROWing Care)
}

\author{
Mark Gilbert ${ }^{1}$ (D) Regina Emily Idoate ${ }^{2} \cdot$ Kenneth Rockwood ${ }^{3}$
}

Received: 6 August 2019 / Accepted: 24 October 2019 / Published online: 6 November 2019

(c) European Geriatric Medicine Society 2019

Keywords Dementia $\cdot$ Portraiture $\cdot$ Art $\cdot$ Aging $\cdot$ Caregiving

The process of creating a portrait relies on a series of intimate interactions. Portraits, even those that depict a single individual, are a visual testament to a relationship. Portrait sitters are required to engage with artists in the creation of their personal visual narrative. As viewers of a portrait, we are invited to actively participate in other's stories, to observe, to question, even stare. This process is integral to the portraits evolving meaning. Giving, receiving, observing $\&$ witnessing care (GROWing Care), the case study presented in this manuscript, draws on these multiple exchanges to explore the experience of dementia and portraiture among older adults and their partners in care as they work with artist/researcher Mark Gilbert, and geriatrician, Kenneth Rockwood.

Previous work with patients and caregivers found that the experience of portraiture in a clinical setting engaged participants in building trusting relationships, embracing uncertainties, exchanging stories, reflecting on experiences and developing a sense of empowerment [1]. In 1998, Rockwood founded the artist-in-residence program at Veterans Memorial Hospital in Halifax. He invited local artists to interpret visually how patients experience living with dementia and

Mark Gilbert

markgilbert@Dal.ca

1 Geriatric Medicine Research, Dalhousie University/Nova Scotia Health Authority, 1427-5955 Veterans' Memorial Lane, Halifax, NS B3H 2E1, Canada

2 Department of Health Promotion, University of Nebraska Medical Center, College of Public Health, 984365 Nebraska Medical Center, Omaha, NE 68198-4365, USA

3 Divisions of Geriatric Medicine and Neurology, Department of Medicine, Dalhousie University/Nova Scotia Health Authority, 1427-5955 Veterans' Memorial Lane, Halifax, NS B3H 2E1, Canada how dementia is treated. Their artworks, now exhibited on the walls of the hospital's Memory Clinic, contribute to the clinical program by enhancing the therapeutic ambiance, diminishing the anxiety of those visiting the clinic and enabling greater insight into the patient experience [2].

GROWing Care, portrays one of Rockwood's patients, Emily (a 78-year-old woman diagnosed with dementia in 2011) (Fig. 1), and Dawson (an 80-year-old man, Emily's husband and partner in care) (Fig. 2) Mark visited them both at home seven times, over 3 months. Rockwood accompanied Mark to one meeting. During these visits, after coffee, cookies and chatting at their kitchen table, Mark drew them, one at a time. On the days he drew Dawson, Emily often went next door to play the piano in the living room. On the days he drew Emily, Dawson regularly observed the portraiture session, tended to household chores and engaged in conversation with Emily and Mark. The conversations between Mark, Rockwood, Dawson and Emily were audio recorded and transcribed. These transcriptions, along with Emily and Dawson's portraits and Mark's associated journal entries constitute the GROWing Care data reported on in this case study.

During sittings, Emily and Dawson reflected on their relationship, and life growing up. They were eager to emphasize that despite Emily's diagnosis they continue to mutually care for and support one another. They reminisced about times when Emily had to look after Dawson when he was being treated for prostate cancer. Emily poignantly stated "I just hope I die before you. Because if you're not there, I don't know what I'll do." Later Dawson pointedly explained, "it's not me taking care of [Emily] or [Emily] taking care of me, it's a team of two". Sitting for their portrait allowed space for reflection on life with memory loss. Mark observed how Dawson gently corrected Emily when she forgot something. At one point Emily said to Mark, "the trouble is my short 


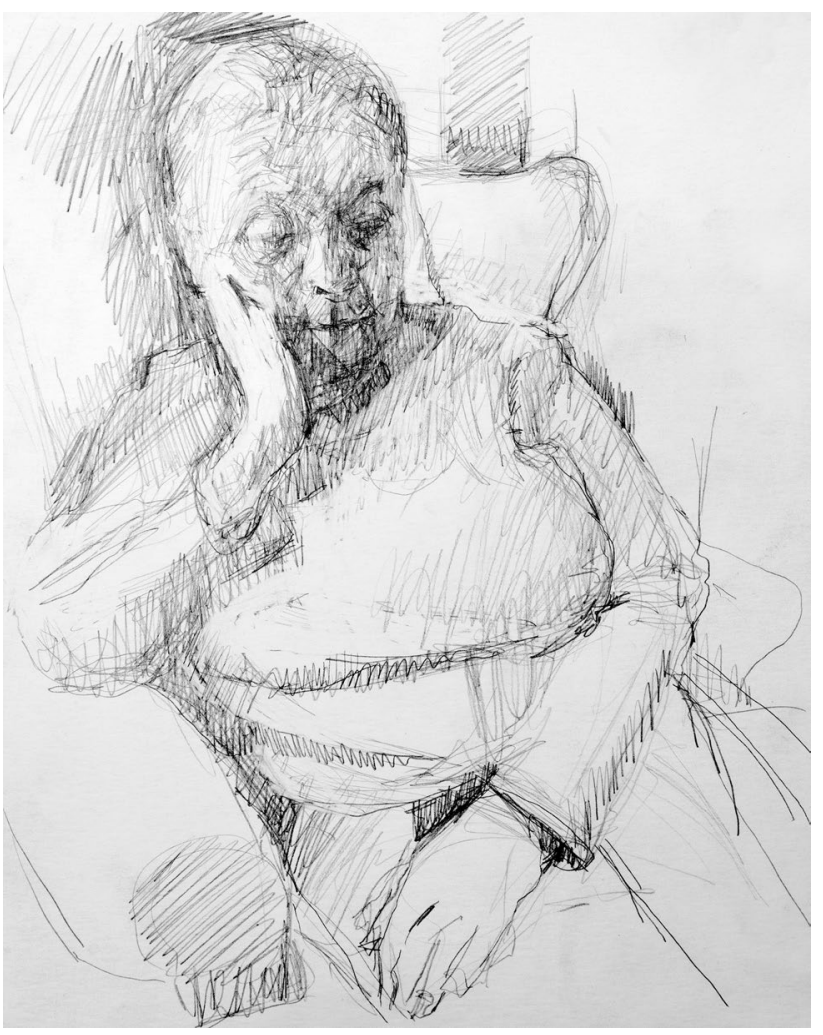

Fig. 1 Emily, pencil on paper, 2019

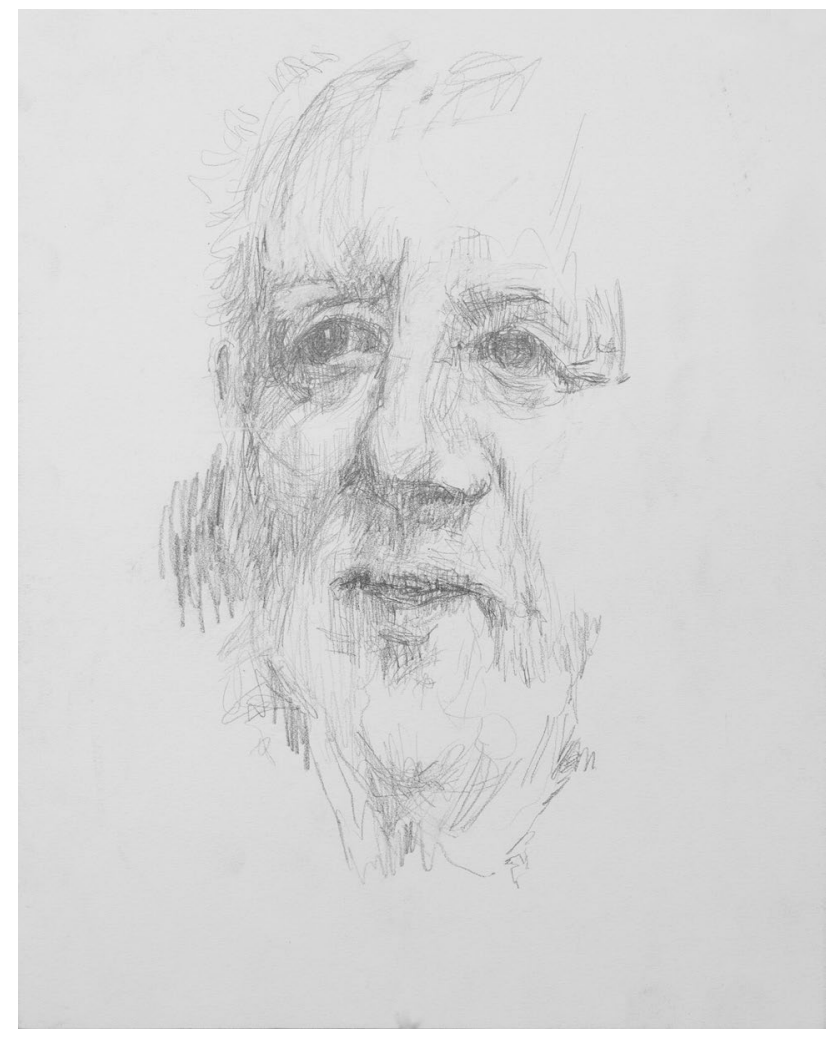

Fig. 2 Dawson, pencil on paper, 2019 term memory is very bad, and I can't argue with people because they might be right and I'm wrong." On another occasion, Emily shared with her husband, "my memory's terrible...Oh gosh, Dawson, I don't remember what day of the week it is." These feelings expressed in words are also evidenced in the portrait "Emily and Dawson" (Fig. 3), in the way Emily and Dawson sit at their kitchen table. Emily, with soft shoulders, holds her face with a gentle smile of acceptance while Dawson, more upright, looks at the viewer with a guarded curiosity. The viewer is able to trace "the route of the work" as it adumbrates a "semblance" of their experience. As such the portrait has the capacity to not merely record, but to evoke and inspire [3].

People with dementia and their carer(s) remember and describe "while engaged in social interactions" [4]. Social interactions between Rockwood, Mark, Emily and Dawson produced data that demonstrates that through the process of portraiture, sitters can observe and get to know not only themselves but also the artist and their physician. Mark told Emily and Dawson, “As I'm drawing, I'm also getting to know you a little bit better." Dawson described the importance of such relationship building when in describing Rockwood, he said, "because of the patients he's dealing with, it requires time to understand what's going on inside the mind. Whereas... the surgeon, I mean he's a mechanic.... He's done some pretty interesting things to my body. But he's a mechanic." A mechanical artist, like a surgeon, may not get to know subjects on a personal level. This depth of familiarity echos Gilbert's prior relationships with sitters and mirrors the relationships that develop between patients and caregivers [5]. As Rockwood said, working in medicine is "paying attention." He explained, "my job is to listen to symptoms." At a sitting with Emily and Dawson,

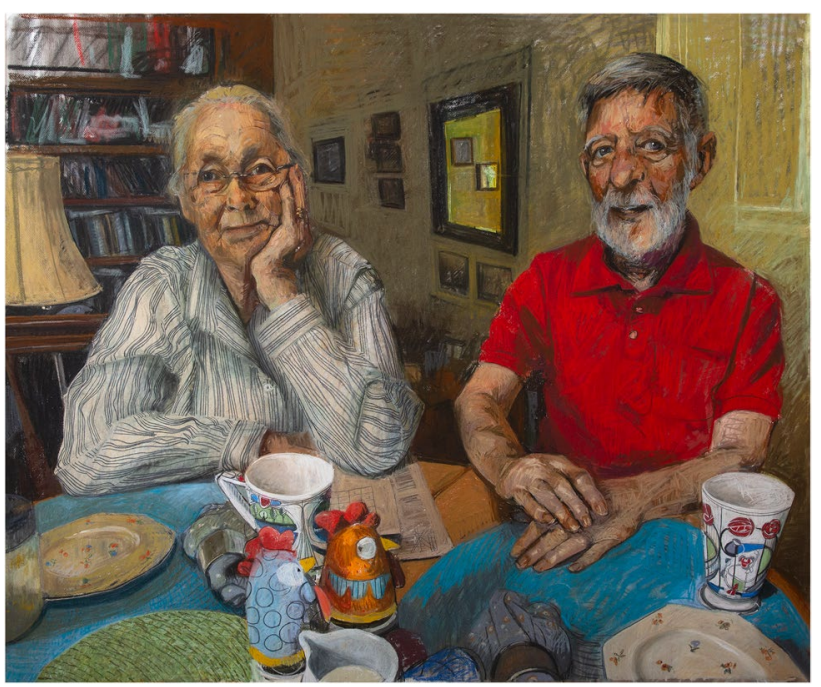

Fig. 3 Emily and Dawson, pastel on paper, 2019 
Rockwood said, "here, everyone gets a vote." Emily and Dawson actively contributed to their portraits, expressing themselves, reflecting, contemplating and telling their own story. Gilbert, listened, absorbed what he heard, saw and felt to help guide the marks he made on the paper.

GROWing Care's interdisciplinary analysis team continues to consider how the portrait making process and the resultant images can contribute to our understanding of the relationships among carers and older adults living with dementia. We hope the findings of the resultant exhibition of the study portraits will not just inform, but also inspire us to reconsider the relationship between those who give and receive and observe and witness care. We believe attention to these relationships can help reframe our perspective of the lives of older adults and people living with dementia in ways that can challenge and stimulate and nurture fresh thinking, dialogue and connections.

Funding The study was funded with the assistance of Fountain Family Innovation Fund (QEII Health Sciences Centre Foundation).

\section{Compliance with ethical standards}

Conflict of interest On behalf of all authors, the corresponding author states that there is no conflict of interest.
Ethical standards This article does not contain any studies with animals performed by any of the authors. All aspects of the study were approved by Research Ethics Board (REB) at Nova Scotia Health Authority.

Informed consent Informed consent was obtained from all individual participants included in the study. Additional informed consent was obtained from all individual participants for whom identifying information is included in this article.

\section{References}

1. Gilbert MA, Lydiatt WM, Aita VA, Robbins RE, McNeilly DP, Desmarais MM (2016) Portrait of a process: arts-based research in a head and neck cancer clinic. Med Humanit (BMJ) 42(1):57-62

2. Rockwood K (2004) Lending a helping eye: artists in residence at a memory clinic. Lancet Neurol 3(2):119-123

3. Radley A (2009) Works of illness: narrative, picturing and the social response to serious disease. InkerMen Press, Ashby-de-laZouch, England

4. Basset R, Graham JE (2007) Memorabilities: enduring relationships, memories and abilities in dementia. Ageing Soc 27(4):533-554

5. Aita V, Lydiatt W, Gilbert M (2010) Portraits of care: medical research through portraiture. Med Humanit (BMJ) 36(1):5-13

Publisher's Note Springer Nature remains neutral with regard to jurisdictional claims in published maps and institutional affiliations. 